\title{
Biting behavior of Malaysian mosquitoes, Aedes albopictus Skuse, Armigeres kesseli Ramalingam, Culex quinquefasciatus Say, and Culex vishnui Theobald obtained from urban residential areas in Kuala Lumpur
}

Chee Dhang Chen ${ }^{\mathrm{a}}$, Han Lim Lee ${ }^{\mathrm{b}}$, Koon Weng Lau ${ }^{\mathrm{a}}$, Abdul Ghani Abdullah ${ }^{\mathrm{b}}$, Swee Beng Tan ${ }^{\mathrm{b}}$, Ibrahim Sa’diyah $^{\mathrm{b}}$, Yusoff Norma-Rashid ${ }^{\mathrm{a}}$, Pei Fen Oh${ }^{\mathrm{a}}$, Chi Kian Chan ${ }^{\mathrm{b}}$, Mohd Sofian-Azirun ${ }^{\mathrm{a}}$

anstitute of Biological Sciences, Faculty of Science, University of Malaya, Kuala Lumpur 50603, ${ }^{b}$ Medical Entomology Unit, WHO Collaborating Center for Vectors, Institute for Medical Research, Jalan Pahang, Kuala Lumpur 50588, Malaysia

\begin{abstract}
Background: There are several species of mosquitoes that readily attack people, and some are capable of transmitting microbial organisms that cause human diseases including dengue, malaria, and Japanese encephalitis. The mosquitoes of major concern in Malaysia belong to the genera Culex, Aedes, and Armigeres.

Objective: To study the host-seeking behavior of four Malaysian mosquitoes commonly found in urban residential areas in Kuala Lumpur.

Methods: The host-seeking behavior of Aedes albopictus, Armigeres kesseli, Culex quinquefasciatus, and Culex vishnui was conducted in four urban residential areas in Fletcher Road, Kampung Baru, Taman Melati, and University of Malaya student hostel. The mosquito biting frequency was determined by using a bare leg catch (BLC) technique throughout the day (24 hours). The study was triplicated for each site.

Results: Biting activity of Ae. albopictus in urban residential areas in Kuala Lumpur was detected throughout the day, but the biting peaked between 0600-0900 and 1500-2000, and had low biting activity from late night until the next morning (2000-0500) with biting rate $\leq 1$ mosquito/man/hour. Biting behavior of Ar. kesseli was distinctly crepuscular, which exhibited two peaks of activity at 0600-0700 and 1900-2000, while Culex quinquefasciatus and $C x$. vishnui were nocturnal feeders with multiple biting peaks throughout the night.

Conclusion: This study recommends optimal time for fogging to be conducted in Malaysia and neighboring countries according to the peak biting peak obtained.
\end{abstract}

Keyword: Aedes albopictus, Armigeres kesseli, Culex quinquefasciatus, Culex vishnui, host-seeking behavior

Most species of Malaysian mosquitoes are relatively uncommon and seldom pose a threat to the health or well-being of Malaysian citizens. However, there are several species of mosquitoes that readily attack people, and some are capable of transmitting microbial organisms that cause human diseases such as dengue, malaria, and Japanese encephalitis. The mosquitoes of major concern in Malaysia belong to the genera Culex, Aedes, and Armigeres.

Aedes albopictus is an important vector transmitting dengue hemorrhagic fever and dengue

Correspondence to: Chen Chee Dhang, Institute of Biological Sciences, Faculty of Science,University of Malaya, Kuala Lumpur 50603, Malaysia. E-mail: chen_ctbr@um.edu.my fever (DF) in Malaysia [1, 2]. A total of 66,055 of DF cases were reported with 170 mortalities from year 2010 to 2011 in Malaysia [3, 4].

Culex mosquitoes are the major vectors of filariasis and Japanese encephalitis [5]. Culex quinquefasciatus is the most common Malaysian household nuisance mosquito as reported by Yap et al. [6]. It is also a potential vector of urban lymphatic filariasis caused by the nematode parasite Wuchereria bancrofti [7]. Culex vishnui is one the vectors of Japanese encephalitis (JE) in Southeast Asia and its abundance is related to rice cultivation $[8,9]$. In this study, $C x$. vishnui was only collected from urban residential areas that had high vegetation, such as Fletcher Road and Taman Melati, Kuala Lumpur. 
Armigeres mosquitoes have been reported to be vectors of lymphatic filariasis and animal filariasis [10, 11]. The two common Armigeres species that are commonly found in Malaysia are Armigeres kesseli and Armigeres subalbatus [12]. Armigeres subalbatus had been proven to be a good host of Brugia malayi that cause human and animal filariasis [11]. Armigeres subalbatus was also an important vector of the dog heartworm in urban Kuala Lumpur [13]. Chen et al. [14] concluded that JE was likely transmitted between vertebrate hosts by $A r$. subalbatus in rice-islet and should be considered as a potential vector in similar ecological conditions.

Host-seeking behavior or biting behavior of different species mosquitoes has been well documented. However, all these studies were conducted in countries outside Malaysia, including Brazil [15], Nigeria [16], The Philippines [17], Thailand $[18,19]$, and India [20, 21], all having different timing of sunrise and sunset. In addition, the timing as mentioned by the above researchers may not correspond to the standard regional time. This may affect the timing of local authorities to conduct vector control activities, especially fogging. According to Charlwood et al. [22], light intensity controls biting activity of mosquitoes to a very fine degree. In other words, the host-seeking behavior of mosquitoes would likely depend on the presence of sunlight during sunrise and sunset. This study reported the host-seeking behavior of four mosquito species commonly found in urban residential areas in Malaysia.

\section{Materials and methods}

Four urban residential areas, namely Fletcher Road (N3¹0'24.10", E10142'30.86"), Kampung

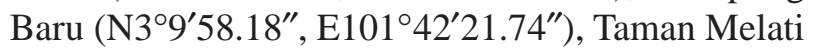
(N3 $\left.{ }^{\circ} 13^{\prime} 16.94^{\prime \prime}, \mathrm{E} 101^{\circ} 43^{\prime} 25.82^{\prime \prime}\right)$ and University of Malaya student hostel (N37'34.64", E101³9'38.67") were selected for this study from May to June 2008. The mosquito biting behavior was studied by using a bare leg catch (BLC) technique as outlined by Haddow [23]. BLC was conducted for 24 hours and divided into 2 shifts (0700-1900 and 1900-0700) during the trial with potential collectors sitting near mosquito breeding or resting sites. All collection was conducted outdoors. After providing written informed consent for participation in the study, volunteers collected the mosquitoes using glass tube $(50 \mathrm{~mm} \times 19 \mathrm{~mm})$ once they landed and subsequently plugged the tubes with cotton. The captured mosquitoes were identified and segregated in batches hourly over 24 hours. The collection was repeated in triplicate within a week for each site. Cross reference was done for identification with collections from Institute for Medical Research (IMR), Kuala Lumpur, using a pictorial key to identify mosquitos [24] and the keys of Triplehorn and Johnson [25].

\section{Results and discussion}

Figure 1 shows the biting activity of Ae. albopictus obtained from four urban residential areas in Kuala Lumpur. Three biting peaks of Ae. albopictus occurred in the Fletcher Road location (0800-0900, 1600-1700, 1900-2000) and the University of Malaya student hostel (1000-1100, 1600-1700, 1800-1900), while only two biting peaks were seen in the Taman Melati location (0600-0700, 1800-1900), and Kampung Baru (0800-0900, 1800-1900). Generally, biting activity of Ae. albopictus in urban residential areas of Kuala Lumpur was detected throughout the day, but it was highly active between 0600-0900 and 1500-2000, and had low biting activity from late night till next morning (2000-0500) with biting rate $\leq 1$ mosquito/man/hour. Our finding was supported by Xue and Barnard [26], who reported that the biting behavior of Ae. albopictus was bimodal during diel period; attack rates were higher in the morning (0800) and evening (1400-2000) and lowest at 0200-0600. Marques and Gomes [15] reported the biting activity of Ae. albopictus took place during the day, which peaked at 0600-0700, 1300-1400 and was highest between 1600 and 1700. In Thailand, Thavara et al. [18] also reported that the biting activity of Aedes mosquitoes was higher in the morning and afternoon from 0800 to 1700; with low prevalence between 1300 and 1400. Although Ae. albopictus has been reported as a day time feeder [27], a low number of $A e$. albopictus was also collected during nighttime (average $\leq 1 \mathrm{mosquito/man/hour).} \mathrm{This} \mathrm{may} \mathrm{be} \mathrm{the}$ result of the influence of light on Ae. albopictus from houses near to our sampling station. In addition, our study sites consisted of housing areas that were overgrown with shrubs and vegetation that also provided an ideal resting site for this daytime biter. Koehler and Castner [27] reported that Ae. albopictus is a day time feeder and can be found in shady areas where it rests in shrubs near the ground. Vegetation plays an important role because it provides nectar sources for sugar feeding and resting sites for Ae. albopictus [28, 29]. Que et al. [30] also mentioned 
that the presence of vegetation is an important determining factor for the presence of Ae. albopictus. Thus, the low biting rate of Aedes during late night until early morning may be the result of the resting habits of Ae. albopictus on vegetation near to the sampling station.

Armigeres kesseli was only collected from three residential areas and the biting activity of Ar. kesseli is shown in Figure 2. Results obtained from all study sites exhibited a similar trend of biting activity with two peaks at 0600-0700 and 1900-2000. Ar. kesseli was seen actively seeking hosts for blood source before sunrise and the number of Ar. kesseli began to decrease once the sun rose. No Ar. kesseli was seen throughout the daytime until sunset at 1800 . Higher biting peak was observed after sunset between 1900-2000, compared with early morning (0600-0700) activity in all study sites. Biting behavior of Ar. kesseli as shown in this study was distinctly crepuscular, exhibiting two peaks of activity similar to those reported by Pandian and Chandrashekaran [21]. According to Ramalingam [31], Armigeres species is a semidomestic species of which the larvae bred in coconut shells, bamboo stumps, leaf axils, and rotting fruits, and the larvae could tolerate highly polluted water bodies.

Biting activity of $C x$. quinquefasciatus obtained from four urban residential areas in Kuala Lumpur was presented in Figure 3. Cx. quinquefasciatus began to seek hosts after 1800 until the next morning before 0700 . Generally, $C x$. quinquefasciatus is a nocturnal biter with multiple biting peaks throughout the night. There were two and three biting peaks of Cx. quinquefasciatus in Kampung Baru (2100-2200 and 0300-0400), Fletcher Road (2100-2200, 01000200, and 0300-0400), and Taman Melati (2100-2200, 0100-0200, and 0300-0400), respectively, while the biting peaks obtained from the University of Malaya student hostel fluctuated throughout the night. Therefore, $C x$. quinquefasciatus is a nocturnal feeder because no biting activity was observed from 0700 to 1800 as reported by Richard and David [32]. Rozandaal [33] also found that $C x$. quinquefasciatus was inactive during daytime and rested in dark corners of rooms, shelters, and culverts as well as in vegetation and tree holes. Our study showed some differences in $C x$. quinquefasciatus biting peak as also reported by Sucharit et al. [19] who showed that there were two minor peaks on top of the nocturnally periodic peak, of which the first peak was between 2200-2300, the latter peak was after midnight at 0100-0400. Mahanta et al. [34] reported that the biting activity was seen throughout the night with declining trend as the night proceeded, which was similar to our finding. Another study conducted in Benin City of Nigeria by Aigbodion and Emiebor [16] showed that April, May, and June possessed a two-hour biting peak from 0000 to 0200 , while only a one-hour biting peak from 0100 to 0200 was observed in March, July, August, and September. However, this aspect of mosquito biting behavior was not examined in this study and remains to be investigated in this region.

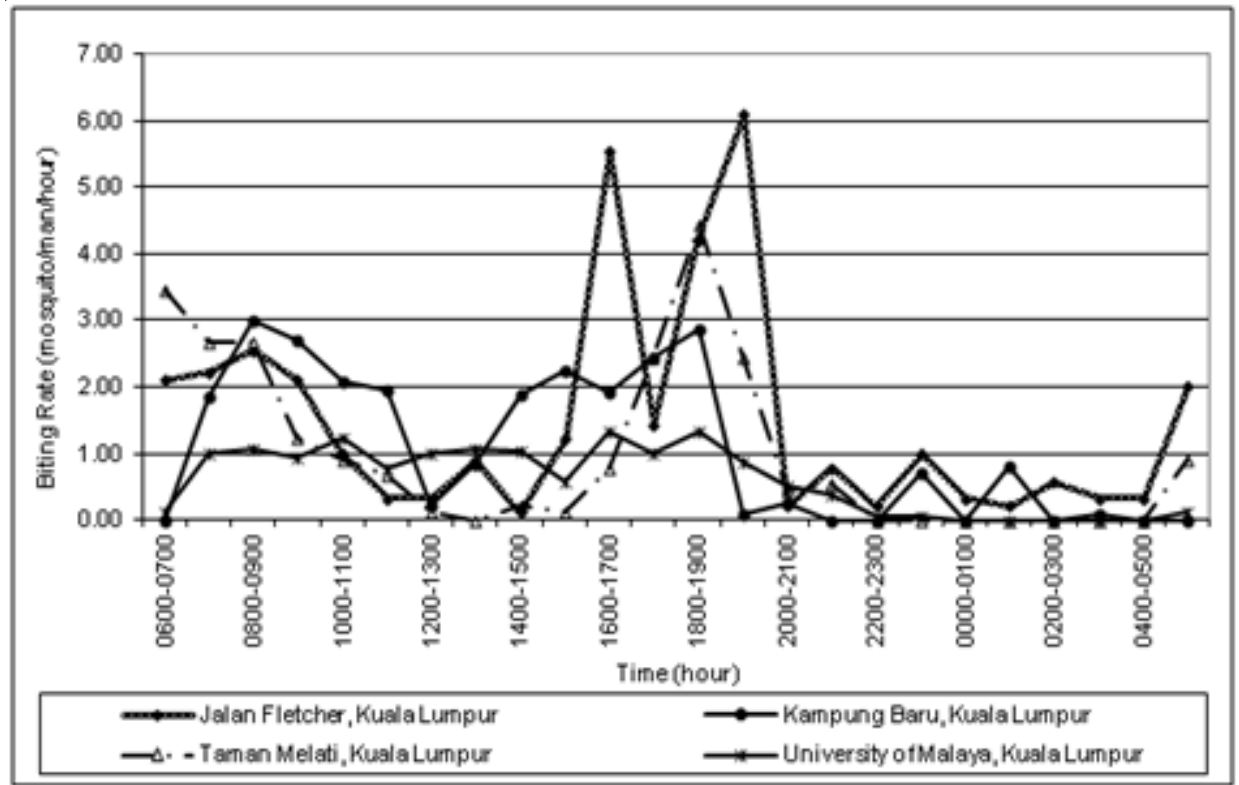

Figure 1. Biting activity of Aedes albopictus obtained from urban residential areas in Kuala Lumpur, Malaysia 


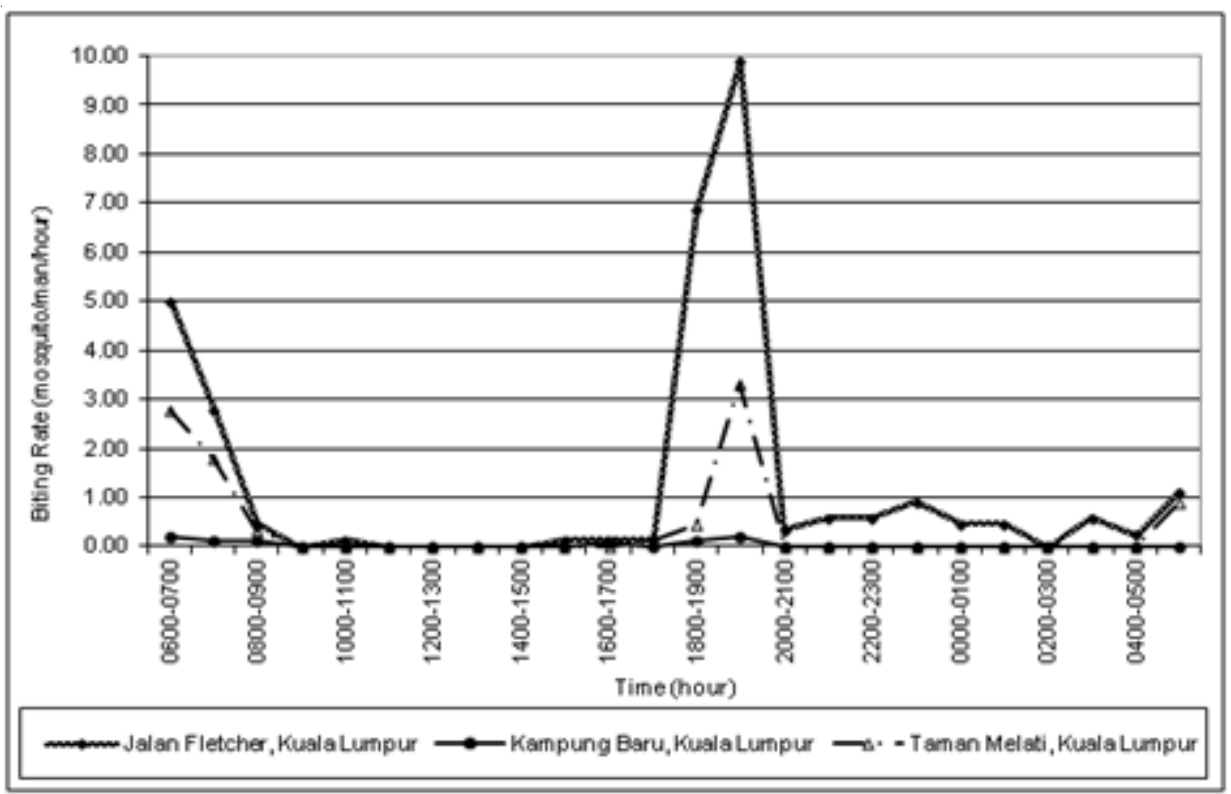

Figure 2. Biting activity of Armigeres kesseli obtained from urban residential areas in Kuala Lumpur, Malaysia

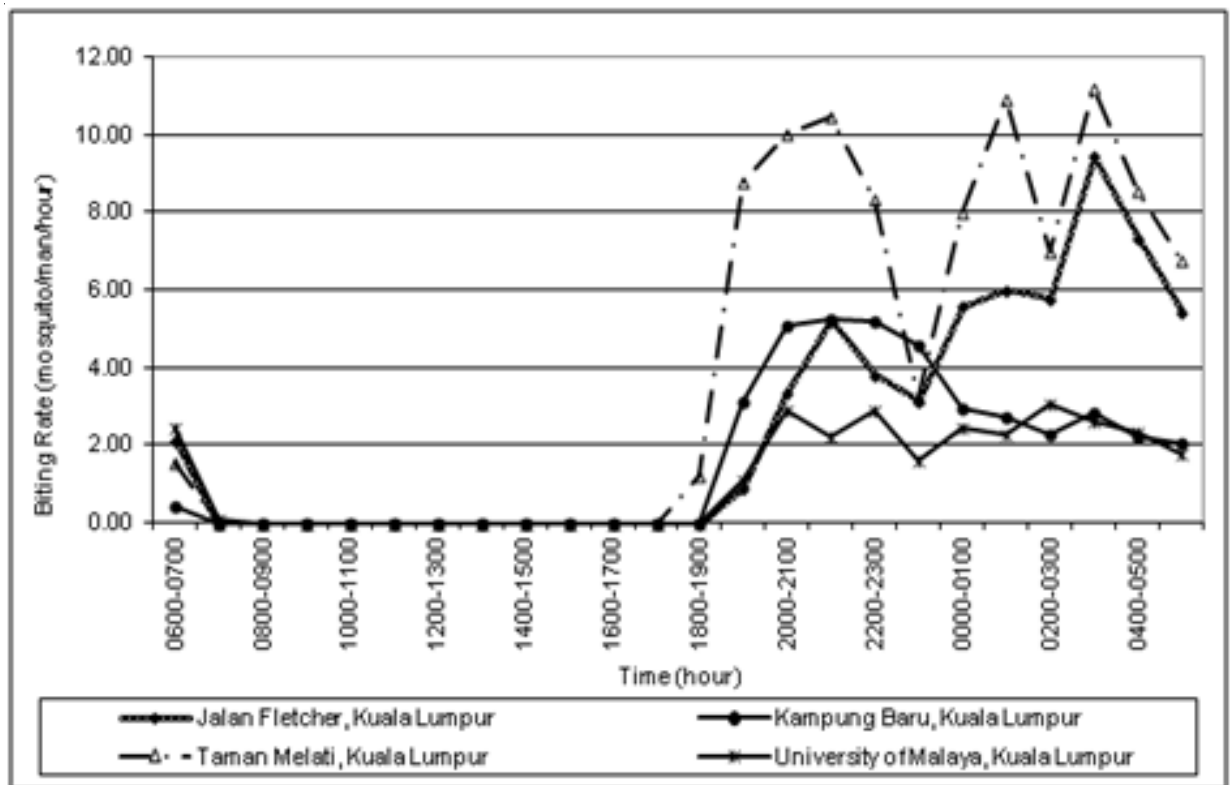

Figure 3. Biting activity of Culex quinquefasciatus obtained from urban residential areas in Kuala Lumpur, Malaysia 


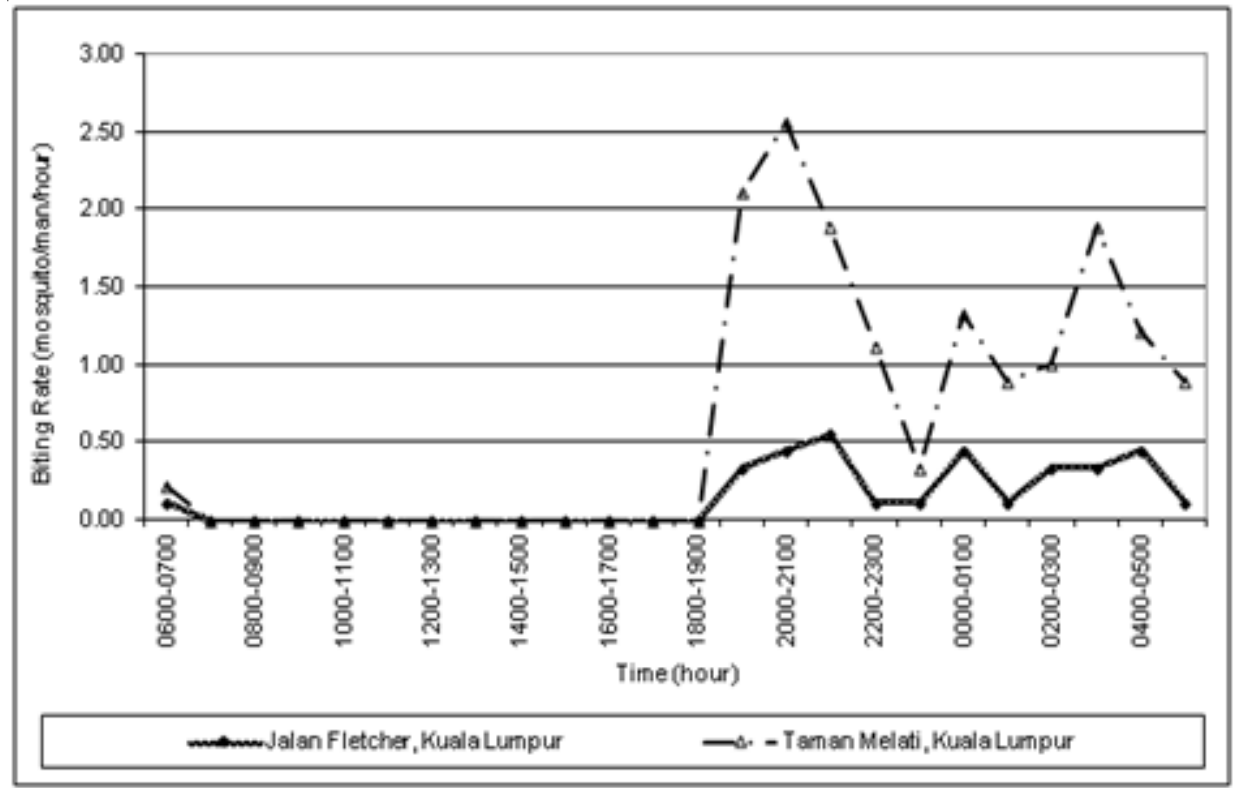

Figure 4. Biting activity of Culex vishnui obtained from urban residential areas in Kuala Lumpur, Malaysia

Culex vishnui was only collected from two residential areas (Fletcher Road and Taman Melati) and the biting activity of this mosquito is shown in Figure 4. Culex vishnui exhibited similar trend of biting activity as $C x$. quinquefasciatus, with multiple biting peaks throughout the night, and began to seek for host after 1800 until the next morning before 0700 . Three major biting peaks for $C x$. vishnui were detected from Fletcher Road (2100-2200, 0000-0100, and 0400-0500), and Taman Melati (2000-2100, 0000-0100, and 0300-0400). Our result was supported by Shultz and Hayes [17] who reported that $C x$. vishnui fed primarily from 1800 throughout the night. Reuben [20] also reported that the $C x$. vishnui group achieved a maximum biting rate between 2200 and 0000 and the biting activity declined throughout the nocturnal period and ceased at dawn.

\section{Conclusion}

In conclusion, Ae. albopictus was categorized as an active daytime feeder while Ar. kesseli was a crepuscular biter, active at dusk and dawn. Culex quinquefasciatus and $C x$. vishnui were both nighttime feeders. The recommended optimal time to conduct fogging in Malaysia according to the biting peak obtained from this study is shown in Table 1. Similar recommendation may also be useful to neighboring countries that have similar sunset and sunrise timing as Malaysia, such as Singapore, and southern regions of Thailand. The realization of the process of finding and taking a blood meal has provided a useful and, indeed, essential operational premise in the effort to control the mosquito-borne diseases. Understanding the biting activity of mosquitoes is an approach to enhance the effectiveness of integrated

Table 1. Recommend timing to conduct fogging in Malaysia according to the biting peak obtained from this study

\begin{tabular}{llcc}
\hline Category & Genus & \multicolumn{2}{c}{ Recommend timing to conduct fogging programme } \\
\cline { 3 - 4 } & & $\mathbf{1}^{\text {st }}$ recommendation & $2^{\text {nd }}$ recommendation \\
\hline Daytime biter & Aedes & $1800-2000$ & $0500-0700$ \\
Crepuscular biter & Armigeres & $1900-2000$ & $0600-0700$ \\
Nighttime biter & Culex & $2000-2200$ & $0300-0500$ \\
\hline
\end{tabular}


vector management (IVM). The data obtained from this study helps to determine the correct timing for fogging operation in order to maximize the mortality of the targeted mosquitoes. In addition, the biting peak of mosquitoes indicated the critical time for blood feeding, and is therefore the high risk period for disease transmission from mosquitoes to human to occur. Thus, public awareness of these facts helps to promote the use of personal protection measures against diseases transmitted by mosquitoes.

\section{Acknowledgement}

The authors are grateful to the staff of the Medical Entomology Unit, Institute for Medical Research for their assistance in the field. This study was supported financially by University of Malaya Research Grant (UMRG Project No. RP003C/13SUS and RG209/13SUS). Informed consent was obtained from the staff using the prescribed form as stipulated in WHO guidelines [35], in accordance to Standard Operation Procedures of our Institute for Medical Research (IMR/IDRC/ENTO/SOP/20). The authors have no conflicts of interest to declare.

\section{References}

1. Lam SK. Two decades of dengue in Malaysia. Trop Biomed. 1993; 10:195-200.

2. Chen CD, Seleena B, Mohd Masri S, Chiang YF, Lee HL, Nazni WA, et al. Dengue vector surveillance in urban residential and settlement areas in Selangor, Malaysia. Trop Biomed. 2005; 22:39-43.

3. Ministry of Health, Malaysia. Press Release 2010. Disease Control Division, Ministry of Health, Malaysia. 2010.

4. Ministry of Health Malaysia. Situasi semasa deman denggi di Malaysia bagi minggu 52/2011. Kenyataan Akhbar Ketua Pengarah Kesihatan Malaysia. 2011. p. 1-4.

5. Hemingway J, Ranson $\mathrm{H}$. Insecticide resistance in insect vectors of human disease. Annu Rev Entomol. 2000; 45:371-91.

6. Yap HH, Zairi J, Jahangir K, Adanan CR. Culex: mosquitoes that spread Japanese Encephalitis. In: Ng FSP, Yong HS, editors. Mosquitoes and mosquitoborne diseases. Kuala Lumpur: Academic Science Malaysia; 2000. p. 73-9.

7. Vythilingam I, Tan CH, Nazni WA. Transmission potential of Wuchereria bancrofti by Culex quinquefasciatus in urban areas of Malaysia. Trop Biomed. 2005; 22:83-5.
8. Stoops CA, Gionar YR, Shinta SP, Rusmiarto S, Susapto D, Rachmat A, et al. Larval collection records of Culex species (Diptera: Culicidae) with an emphasis on Japanese encephalitis vectors in rice field in Sukahbumi, West Java, Indonesia. J Vec Ecol. 2008; 33: 216-7.

9. Ganguly NK, Medappa N, Srivastava VK, Singh P, Kant L, Shah B, et al. Japanese encephalitis virus infection in mosquitoes and its epidemiological implications. ICMR Bulletin. 2000; 30.

10. Paily KP, Hoti SL, Das PK. A review of complexity of biology of lymphatic filarial parasites. J Parasite Dis. 2009;33:3-12.

11. Wharton RH. The biology of Mansonia mosquitoes in relation to the transmission of filariasis in Malaya. Bull of the IMR (Malaya). 1962; 11:114.

12. Buckley JJ, Edeson JF. On the adult morphology of Wuchereria sp. (malayi?) from monkey (Macaca irus) and from cats in Malaya, and on Wuchereria pahangi n sp. from a dog and a cat. J Helminth. 1956; 30:1-20.

13. Cheong WH, Mak JW, Naidu S, Mahadevan S. Armigeres subalbatus incriminated as an important vector of the dog heartworm Dirofilaria immitis and the bird Cardiofilaria in urban Kuala Lumpur. Southeast Asian J Trop Med Pub Health. 1981; 12: 611-2.

14. Chen WJ, Ong CF, Chiou LY, Chuang WL. Potential role of Armigeres subalbatus (Diptera: Culicidae) in the transmission of Japanese Encephalitis Virus. In: Absence of rice culture on Liu-Chiu Islet, Taiwan. J Med Entomol. 2000; 1:108-13.

15. Marques GR, Gomes AC. Anthropophilic behaviour of Aedes albopictus (Skuse) (Diptera: Culicidae) in the Vale do Paraiba Region, Southeastern Brazil. Revista de Saude Publica. 1997; 31:125-30.

16. Aigbodion FI, Emiebor GO. Biting cycle of Culex quinquefasciatus (Diptera: Culicidae) in Benin City, Nigeria. Biosci Res Comm. 2008; 20:243-8.

17. Shultz GW, Hayes CG. Ecology of mosquito (Diptera: Culicidae) at a site endemic with Japanese encephalitis on Luzon, Republic of the Philippines. Southeast Asian J Trop Med Pub Health. 1993; 24:157-64.

18. Thavara U, Tawatsin A, Chansang C, Kong-ngamsuk W, Paosriwong S, Boon-Long J, et al. Larval occurrence, oviposition behavior and biting activity of potential mosquito vectors of dengue on Samui Island, Thailand. J Vect Eco. 2001; 26:172-80.

19. Sucharit S, Harinasuta C, Surathin K, Deesin T, Vutikes S, Rongsriyam Y. Some aspects on biting cycles of Culex quinquefasciatus in Bangkok. 
Southeast Asian J Trop Med Pub Health. 1981; 12: 74-8.

20. Reuben R. Studies on the mosquitoes of North Arcot district, Madras state, India: Part 2. Biting cycles and behaviour on human and bovine baits at two villages. J Med Entomol. 1971; 8:127-34.

21. Pandian RS, Chandrashekaran MK. Rhythms in the biting behaviour of a mosquito Armigeres subalbatus. Springer: Berlin/Heidelberg. 1980; 47.

22. Charlwood JD, Lopes J, Whalley PC. Light intensity measurement and the biting behaviour of some sylvatic mosquitoes of Amazon basin (Diptera: Culicidae). Acto Amazonica. 1982; 12:61-4.

23. Haddow AJ. Studies on the biting-habits of African mosquitoes and appraisal of methods employed, with special reference to the twenty-four-hour catch. Bull Entomol Res. 1954; 45:199-242.

24. Choeng WH, Mahadevan S. Entomological charts for teaching. Division of Medical Entomology, I.M.R, Kuala Lumpur. 1970. p. 8-9.

25. Triplehorn CA, Johnson NF. Borror and DeLong's introduction to the study of insects. 7th ed. Belmont, CA: Thomson Brooks/Cole; 2005. p. 699-706.

26. Xue RD, Barnard DR. Human host avidity in Aedes albopictus: influence of mosquito body size, age, parity, and time of day. J Ame Mosq Con Assoc. 1996; 12:58-63.

27. Koehler PG, Castner JL. Blood sucking insects. EDIS [on line]. 2012. [cited 2014 Jun 19]; Available from: http:/edis.ifas.ufl.edu/IN019.
28. Barks MAH, Honorio NA, Lounibos LP, LourecodeOliveira R, Juliano SA. Interspecific competition between two invasive species of container mosquitoes in Brazil. Annal Entomol Socie America. 2003; 97: 130-9.

29. Hawley WA. The biology of Aedes albopictus. J American Mosq Contr Assioc. 1988; 4:1-40.

30. Que ND, Rung D, Chow CY. Aedes surveillance in the republic of Vietnam. Southeast Asian J Trop Med Public Health. 1974; 5:569-73.

31. Ramalingan S. On the restriction of Armigeres durhami Edwards and the description of Armigeres kesseli n. sp. (Diptera: Culicidae). Trop Biomed. 1987; 4:55-6.

32. Richard HF, David RC. Mosquitoes of Medical Importance. Washington D.C.: U.S. Department of Agriculture. 1959.

33. Rozendaal JA. Vector control: method for use by individuals and communities. World Health Organization, Geneva, Switzerland. 1997. p. 52-177.

34. Mahanta B, Handique R, Dutta P, Narain K, Mahanta J. Temporal variations in biting density and rhythm of Culex quinquefasciatus in tea agro-ecosystem of Assam, India. Southeast Asia J Trop Med Pub Health. 1999; 30:804-9.

35. WHO. Guidelines for efficacy testing of insecticides for indoor and outdoor ground-applied space spray application. WHO/HTM/NTD/WHOPES/2009.2. 2009. p. 22-5. 